\title{
Trilateral benefit analysis for medical waste disposal
}

\author{
LIU GUNANGFU ${ }^{1, a}$, XING XIN ${ }^{1, b}$ * \\ ${ }^{1}$ School of economic and management, Tongji University, Shanghai, China 200092 \\ a njauxingxin@163.com, bingxin1991@126.com \\ * please mark the corresponding author with an asterisk
}

Keywords: Medical waste disposal; Benefit analysis; Trilateral benefit; Decision-making.

Abstract. Medical waste disposal is an important problem. This paper firstly analyses the classification and present situation of medical waste disposal, then analyzes problems in the process management, and combine with related data to illustrate the necessity of medical waste disposal. Finally, the balance benefit analysis of hospital, government and the public forms a trilateral game model to achieve maximum expected revenue. Based on trilateral benefit analysis, we can provide a solution, which would offer reference for medical waste disposal.

\section{Introduction}

Along with the speeding up of urbanization, expansion of urban areas and population, the number of various medical institutions is also on the increase. As continuous renewal of medical equipment, medical technology advances, new diagnosis methods are used in disease treatment, the medical waste begin to increase ${ }^{[1]}$. According to the investigation of some big cities, the medical waste discharge of Beijing is $7.503 \mathrm{t} / \mathrm{d}$, Shanghai $45 \mathrm{t} / \mathrm{d}$, Shenzhen $10 \mathrm{t} / \mathrm{d}$, Taiyuan $4.4 \mathrm{t} / \mathrm{d}$. As a result, the quantity of medical is large and wide distribution ${ }^{[2]}$. If they are mishandled and get into illegal collection, it must produce hidden serious danger in regional environment and public health (Figure 1). Therefore, research on the medical waste management recycling has social significance.During recent years, many hospitals in our city have achieved great development in medical waste disposal. However, the model still exists many problems in actual operation, such as limitation of logistics activity, poor service, quality of equipment and so on, it is difficult to achieve efficient disposal and regulation of urban medical waste.

\section{Presentation of medical waste}

Since the 1950s, the world has begun to pay attention to the disposal of medical waste recycle. The United States Environment Protection Agency (USEPA) formulated files about medical waste definitions respectively in 1978 and 199. According to a better understanding of medical waste ${ }^{[3]}$, it is divided into general and special medical waste by the USEPA and WHO (World health organization), and there are detailed introductions and uniformly standards. China enacted Medical Waste Management Regulations in 2003, which firstly give the definition of medical waste [4]. The National Hazardous Waste Directory is enacted by the Environmental Protection Agency, State Economic and Trade Commission in 1998, Clinical waste, waste drug, photosensitive material waste, waste acid-base are first recorded in the content. "Administrative Penalties on Medical Waste management" sequentially set out in 2004, which provided legal protection ${ }^{[5]}$.

From the investigation ${ }^{[6]}$, laboratory waste, surgery dirt, wastewater treatment sludge, stuffed animals must be treated strictly, and disposable plastic, consumable paper product, disposable rubber product, as well as one-time checker can be recycled, which make up 1/3 of medical waste. Medical waste management still exist some secondary pollution problems, which bring great harm to the public health just because of the proper technology As a result, a program that concerns about whole process of medical management is very necessary, and it may change the chaos of the medical waste disposal. Business and service is the key of daily work in the hospital, which produce the medical waste that needs the society to handle, all above activities make up the linear model ${ }^{[7]}$. The recycle 
model adds reverse logistics management, form a closed loop, and recycle the medical produced in the hospitals. In this way, the medical waste not only realizes the effective utilization, but also reduces the harm to the environment and human health and burden on society. With the advanced technology applied in medical treatment, many kinds of medical waste that was regarded as rubbish before has brought huge recycle economic benefits (figure1).

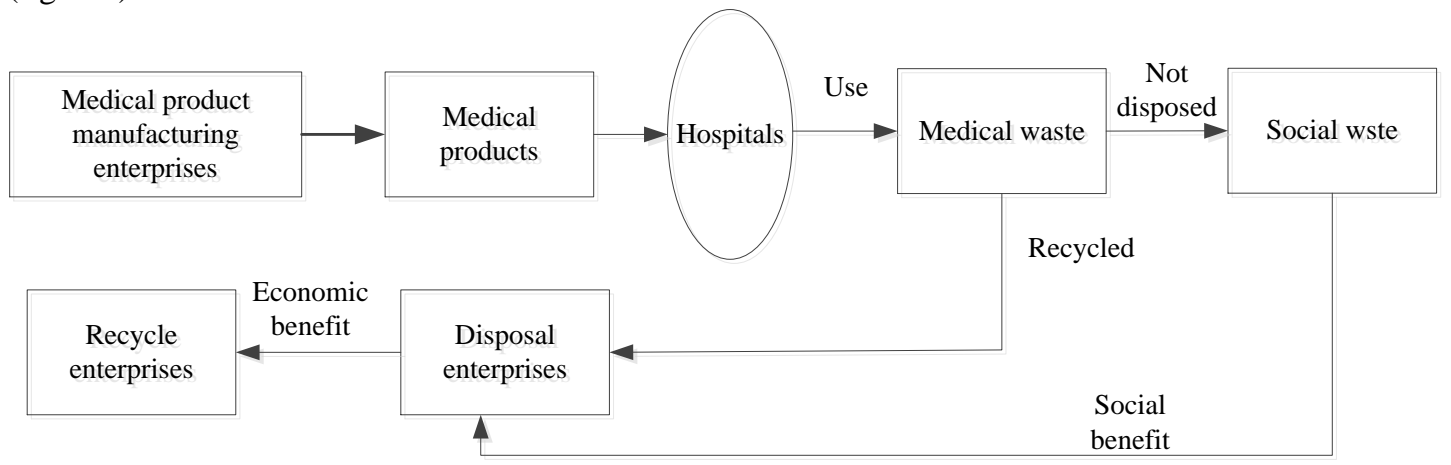

Figure 1 Reverse logistics of medical waste

\section{Game analysis about medical waste management}

\section{Tripartite Game Model}

Assumptions:

1. The cost of government supervision is $\mathrm{C}_{1}$, and the proportion is $\mathrm{P}_{1}$.

2. The cost of hospital that cooperates with government supervision is $C_{2}$, social benefit is $R_{1}$, the proportion is $\mathrm{P}_{2}$. If the hospital just pursuit short-term interests, the penalty is $\mathrm{C}_{3}$, and loss of social image is $R_{2}$.

3. The cost of the public for human rights and complaints that people find unreasonable disposal is $\mathrm{C}_{4}$, and the proportion is $\mathrm{P}_{3}$.

4. Government investigate the accused hospital, the once again penalty is $\mathrm{aC}_{3}(\mathrm{a} \geq 1)$, and social image loss is $b R_{2}(b \geqslant 1)$. The offset for the public is $C_{5}$, the proportion is $\mathrm{P}_{4}$, and the social image that government acquires is $\mathrm{R}_{3}$. If the bribery that the government accepts from hospital is $\mathrm{C}$ and doesn't deal with the accusation, the social image loss is R.

5. When the public don't safeguard right, the government attach great importance to medical waste disposal, the cost is C6, and social earning isR4.

6. If the government don't investigate and the hospital dispose them at will, the social image loss for government is $\mathrm{C} 7$.

Based on the assumptions, the tripartite game model for the government, hospital, and the public is as follows ${ }^{[10]}$.

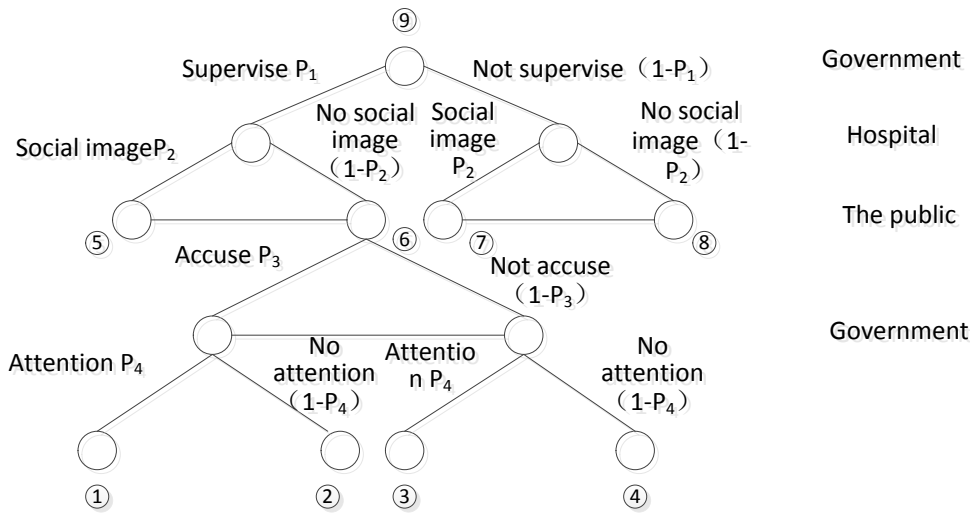

Figure 2 tripartite game model 


\section{Solution of the game model}

Nash equilibrium: Every finite game at least has a mixed strategy Nash equilibrium. For the government, hospital, and the public, everyone wants to get the maximum expectd revenue, but their benefit depends on their own choice on behavioral strategy.

The first stage(Point 6), existing 4 game branches.

The total revenue of government, hospitals and the public at first stage:

$$
\begin{aligned}
& E_{11}=P_{3} P_{4}\left[R_{3}-C_{5}-C_{1}+(1+a) C_{3}\right]+P_{3}\left(1-P_{4}\right)\left(C_{3}-C_{1}+C-R\right) \\
& +\left(1-P_{3}\right) P_{4}\left[R_{4}+(1+a) C_{3}-C_{1}-C_{6}\right]+\left(1-P_{3}\right)\left(1-P_{4}\right)\left(C_{3}-C_{1}\right) \\
& E_{12}=P_{3} P_{4}\left[-(1+a) C_{3}-(1+b) R_{2}\right]+P_{3}\left(1-P_{4}\right) \\
& \left(-C-R_{2}-C_{3}\right)+\left(1-P_{3}\right) P_{4}\left[-(1+a) C_{3}-(1+b) R_{2}\right] \\
& E_{13}=P_{3} P_{4}\left(C_{5}-C_{4}\right)-P_{3}-\left(1-P_{4}\right) C_{4}
\end{aligned}
$$

As for Nash equilibrium, government, hospital and the public all want the maximum expected revenue, so

$$
\frac{\partial E_{11}}{\partial P_{3}}=0, \frac{\partial E_{12}}{\partial P_{4}}=0, E_{13} \geq 0
$$

As a result,

$$
P_{3}=\frac{(1+a) C_{3}+(1+b) R_{2}}{C+R+C_{3}}, P_{4}=\frac{R-C}{R-C+R_{3}-R_{4}+C_{6}-C_{5}}, P_{4} \geq \frac{C_{4}}{C_{5}}
$$

At the second stage (9).

The total revenue of government ,hospital;

$$
\begin{aligned}
& E_{21}=P_{1} P_{2}\left(-C_{1}\right)+P_{1}\left(1-P_{2}\right)+E_{11}{ }^{*}+\left(1-P_{1}\right)\left(1-P_{2}\right)\left(-C_{7}\right) \\
& E_{22}=P_{1} P_{2}\left(R_{1}-C_{2}\right)+P_{1}\left(1-P_{2}\right) E_{12}{ }^{*}+\left(1-P_{1}\right) P_{2}\left(R_{1}-C_{2}\right)
\end{aligned}
$$

As for Nash equilibrium, government, hospital and the public all want the maximum expected revenue, so

$$
\frac{\partial E_{21}}{\partial P_{1}}=0, \frac{\partial E_{22}}{\partial P_{2}}=0
$$

As a result,

$$
P_{1}=\frac{C_{2}-R_{1}}{E_{12}{ }^{*}}, P_{2}=\frac{E_{11}{ }^{*}+C_{7}}{C_{1}+C_{7}+E_{11}{ }^{*}}
$$

\section{Result analysis}

From the point of government, $P_{1}=\frac{C_{2}-R_{1}}{E_{12}{ }^{*}}$ denotes that if hospital pay attention to social image, namely $\mathrm{R}_{1}$ increase, then the proportion of government supervision is small, the cost of medical waste disposal decreases, and the maximum expected revenue $\mathrm{E}_{12}{ }^{*}$ increase, the possibility of government supervision $\left(\mathrm{P}_{1}\right)$ is small. As for $P_{4}=\frac{R-C}{R-C+R_{3}-R_{4}+C_{6}-C_{5}}$, if government strengthens investigation, social image will increase, namely $\mathrm{R} 4, \mathrm{R}$ become larger, and possibility that hospital neglects the regulation becomes small, namely $\mathrm{R}_{3} 、 \mathrm{C}_{6} 、 \mathrm{C}$ is smaller.

From the point of hospital, $P_{2}=\frac{E_{11}{ }^{*}+C_{7}}{C_{1}+C_{7}+E_{11}{ }^{*}}$ denotes that if the government invests more in supervision, the $\mathrm{P}_{2}$ is smaller. If the expected revenue of government $\mathrm{E}_{11}{ }^{*}$ is larger, $\mathrm{P}_{2}$ is also larger. 
From the point of the public, $P_{3}=\frac{(1+a) C_{3}+(1+b) R_{2}}{C+R+C_{3}}$, the public supervision is connected with the government supervision and hospital behavioral strategy. If the government reinforces supervision, $\mathrm{R}$, $\mathrm{R}_{4}$ began to increase, the public motivation increases, namely $\mathrm{P}_{3}$ increase.

\section{Conclusion}

Due to insufficient recognition of medical waste management, the waste can't be correctly disposed and environmental pollution and waste of resources is serious. The main mission of government is to strength supervision and increase the penalty so that the cost of investigation will reduce and social image increases. The government should finitely regulate the standard of medical waste disposal, which can promote the effectiveness of management in the hospital ${ }^{[10]}$. The hospital should pay attention to social image construction and undertake responsibility and the public should get more knowledge of medical waste perniciousness to safeguard their legal rights. According to characteristics of medical waste recycle, the government, hospital and the public should collaborate to build a reasonable medical waste model and spread.

\section{Acknowledgements}

This work was financially supported by the National Social Sciences fund of major Program(12\&ZD073).

\section{References}

[1] Jing L, Xueming L, Ziqiang L. Urban ecological environment evaluation and analysis based on urbanization development systems [J]. China Population Resources and Environment, 2009, 19(1):156-161.

[2] Shu W, Hengshan W, Yunguang W. Regional health coordination mechanism and countermeasure research for resource optimizing configuration [J]. Science and Technology development and Countermeasure, 2010,27(20):38-42.

[3] Jiang C, Ren Z, Tian Y. Application for best available technologies on medical wastes disposal/treatment in China (with case study)[J]. Procedia Environmental Science, 2012,16:257-265.

[4] Ruiqin J, Xinsheng Z. Rise, regulation and development trend of international medical service outsource [J]. International Business Research, 2013,34(3):36-44.

[5] Jin L, Hua W. SDSS for medical waste collection plan [J] Computer Engineering, 2011,37(23):59-64.

[6] Peifen D. Reverse logistics system of medical waste[D]. Dalian:Dalian Maritime University, 2012:60-62.

[7] Bokhoree C, Beeharry Y, Makoondlall-Chadee T, et al. Assessment of Environmental and Health Risks Associated with the Management of Medical Waste in Mauritius[J]. APCBEE Procedia, 2014, 9: 36-41.

[8] Li N. Revelation for China about American medical waste management.[J] Chinese Health Service Mannagement,2014,31(3):30-35.

[9] Hsin P H, Chen C I. Application of Game Theory on Parameter Optimization of the Novel Two-Stage Nash Nonlinear Grey Bernoulli Model[J]. Communications in Nonlinear Science and Numerical Simulation, 2015:90-95. 